Patwardhan, V. N. (1937). Biochem. F. 3r, 560.

Pirzio-Biroli, G., Bothwell, T. H. \& Finch, C. A. (1958). F. Lab. clin. Med. 51, 37.

Pye, O. F. \& MacLeod, G. (1946). F. Nutr. 32, 677.

Ranganathan, S. (1938). Indian $\mathcal{F}$. med. Res. 26, I 19.

Rose, M. S., Vahlteich, E. M. \& MacLeod, G. (1934). F. biol. Chem. 104, 217.

Ruegamer, W. R., Michaud, L., Hart, E. B. \& Elvehjem, C. A. (1946). F. Nutr. 32, Ior.

Sharpe, L. M., Peacock, W. C., Cooke, R. \& Harris, R. S. (1950). F. Nutr. 4x, 433.

Smith, M. C. \& Otis, L. (1937). F. Nutr. 13, 573.

Steinkamp, R., Dubach, R. \& Moore, C. V. (1955). Arch. intern. Med. 95, I81.

Stott, G. (1 960). Bull. Wld Hlth Org. 23, 781 .

Venkatachalam, P. S., Brading, I., George, E. P. \& Walsh, R. J. (1956). Aust. F. exp. Biol. 34, 389.

Walker, A. R. P. \& Arvidsson, U. B. (1953). Trans. R. Soc. trop. Med. Hyg. 47, 536.

Widdowson, E. M. \& McCance, R. A. (1942). Lancet, i, 588.

Widdowson, E. M. \& McCance, R. A. (1954). Spec. Rep. Ser. med. Res. Coun., Lond., no. 287.

Witts, L. J. (1936). Lancet, $i$, 1.

\title{
Relative availability of strontium in flour and milk
}

\section{By T. E. F. Carr, G. E. Harrison, J. F. Loutit and Alice Sutton, Medical Research Council, Radiobiological Research Unit, Harwell, Berks.}

Interest in the turnover of strontium in living material stems from the fact that certain radioactive forms of this element are products of nuclear fission. The longest lived radioactive isotope of $\mathrm{Sr}$ is ${ }^{90} \mathrm{Sr}$ which is potentially one of the most dangerous of the fission products not only because of its long physical half-life ( 28 years) but because like calcium, to which $\mathrm{Sr}$ is chemically related, it is transported along the food chain to man (Comar, Russell \& Wasserman, 1957) and ultimately deposited in bone in close proximity to the radio-sensitive haematopoietic tissue of bone marrow.

The assays of dietary constituents for stable Sr (Bryant, Chamberlain, Spicer \& Webb, I956; Agricultural Research Council Radiobiological Laboratory, I959) have shown that it is widely distributed in human diet. Drinking water also contains $\mathrm{Sr}$, the concentration varying in different parts of the country. For an average diet in the United Kingdom, dairy products and water each account for about $13 \%$ of the total intake of $\mathrm{Sr}$, plants and root vegetables for about $28 \%$ and the fortification of national flour by the addition of creta praeparata (calcium carbonate) for about $40 \%$. The normal dietary intake of $\mathrm{Sr}$ by adults is about $2 \mathrm{mg} /$ day, of which some $90 \%$ is found in the stools and some $10 \%$ in the urine (Harrison, Raymond \& Tretheway, I955; Spencer, Laszlo \& Brothers, 1957).

Although certain claims have been made that $\mathrm{Sr}$ is an essential trace element for plant and animal growth, further evidence is required before an unequivocal conclusion can be made. However, no deleterious effects on growth attributable to the normal abundance of $\mathrm{Sr}$ in the food chain have been reported. The numerous experiments on animals and man designed to limit the gastro-intestinal absorption of $\mathrm{Sr}$ have had as their common object, therefore, a decrease in the uptake of ${ }^{0} \mathrm{Sr}$ which is also a component of contemporary diet.

The advent of nuclear fission has given considerable stimulation to the study of many aspects of gastro-intestinal absorption, mechanisms of kidney filtration, not to mention rates of bone turnover and changes in this turnover with age. Thus, some 
I 800 reports on various aspects of the metabolism of $\mathrm{Sr}$ and $\mathrm{Ca}$ appeared between I 956 and I96I. It is the purpose of this report to present some results of a series of experiments carried out at the Medical Research Council's Radiobiological Research Unit at Harwell on the relative availability to man of Sr from flour and milk (Carr, Harrison, Loutit \& Sutton, I 962). 'To understand the reasons for such an investigation we must refer to earlier studies on the availability of $\mathrm{Ca}$.

Mellanby (1925) originally observed an anticalcifying and rachitogenic power of certain cereals when given to puppies, and Bruce \& Callow (1934) and McCance \& Widdowson (1942-3) identified phytic acid (inositolhexaphosphate) as the responsible agent. With wheat, the phytic acid content increases with the degree of extraction and consequently in Britain during World War II, when only high-extraction flour was available, creta praeparata was added to supplement the dietary $\mathrm{Ca}$. It is now known that the addition of phosphate or sodium phytate to the diet decreases the gastro-intestinal absorption of Sr (Wasserman \& Comar, r960; Kostial, Lutkić, Grunden, Vojvodić \& Harrison, I963). What was unknown, was whether the Sr in wheat flour was chemically bound as an insoluble phytate so that it passed through the digestive tract without chemical change and so was unavailable. If stable $\mathrm{Sr}$ was so bound, ${ }^{90} \mathrm{Sr}$ would be unavailable as well and added protection against the uptake of ${ }^{90} \mathrm{Sr}$ would thus be obtained from a cereal-rich diet, such as, for example, that of many Eastern civilizations.

\section{General plan of the experiment}

Five male adults from this Laboratory went on the constant diet shown in Table I for $2 \mathrm{I}-32$ days. The main constituents of this diet were milk and unfortified bread. The relative availability of $\mathrm{Sr}$ from bread was compared with that from milk by using two different radioactive isotopes of $\mathrm{Sr}$ which could be readily distinguished by physical means. Thus, the bread was made from wheat grown on an experimental reserve by the Radiobiological Laboratory of the Agricultural Research Council. The experimental flour contained about ten times as much ${ }^{90} \mathrm{Sr}$ as current British flour. The milk was obtained from a cow which had been given a parenteral dose of

Table I. Constitution of the experimental diet with the levels of radioactive strontium in the different constituents

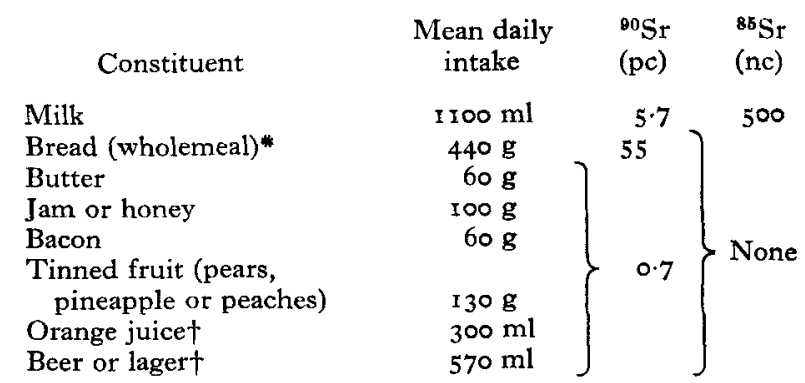

*For two subjects, F.S.W. and G.R.H., the ${ }^{90} \mathrm{Sr}$ in the flour was somewhat lower and the daily intake of ${ }^{90} \mathrm{Sr}$ was $45 \mathrm{pc}$.

fOptional extras including tea or coffee infusions with distilled water. 
Table 2. Weekly intake (I) and urinary output (U) of ${ }^{90} \mathrm{Sr}$ (bread) and ${ }^{85} \mathrm{Sr}$ (milk) with the ratio, $\left({ }^{U} / 1\right)^{90} \mathrm{Sr}:\left({ }^{U} / 1\right)^{85} \mathrm{Sr}$ for subjects on the experimental diet

\begin{tabular}{|c|c|c|c|c|c|c|c|c|}
\hline \multirow{3}{*}{ Subject } & \multicolumn{4}{|c|}{${ }^{90} \mathrm{Sr}$} & \multicolumn{3}{|c|}{${ }^{85} \mathrm{Sr} *$} & \multirow{2}{*}{$\begin{array}{c}\text { Ratio, } \\
\left(\frac{U}{I}\right)^{90} \mathrm{Sr}:\left(\frac{U}{I}\right)^{85} \mathrm{Sr}\end{array}$} \\
\hline & on & $\begin{array}{c}I \\
(\mathrm{pc})\end{array}$ & $\begin{array}{c}U \\
(\mathrm{pc})\end{array}$ & $U: I \times 10^{2}$ & $\begin{array}{c}I \\
(\mathrm{nc})\end{array}$ & $\begin{array}{c}U \\
(\mathrm{nc})\end{array}$ & $U: I \times 10^{2}$ & \\
\hline & I & 438 & 30 & 6.8 & 3500 & 262 & $7 \cdot 5$ & 0.90 \\
\hline \multirow{3}{*}{ T.E.F.C. } & 2 & 456 & 40 & 8.8 & 3500 & 415 & $11 \cdot 9$ & 0.74 \\
\hline & 3 & 448 & 40 & $8 \cdot 9$ & 3500 & $45^{6}$ & 13.0 & 0.69 \\
\hline & 4 & 432 & 36 & $8 \cdot 3$ & 3500 & 447 & $12 \cdot 8$ & 0.65 \\
\hline \multirow{5}{*}{ G.E.H. } & $\mathbf{I}$ & 444 & 18 & $4 \cdot I$ & 3500 & 124 & $3 \cdot 5$ & $\mathrm{I} \cdot \mathrm{I} 7$ \\
\hline & 2 & $43^{8}$ & 30 & $6 \cdot 8$ & 3500 & 198 & $5 \cdot 7$ & $1 \cdot 19$ \\
\hline & 3 & 442 & 26 & $5 \cdot 9$ & 3500 & 202 & $5 \cdot 8$ & $1 \cdot 02$ \\
\hline & 4 & $4 \mathrm{I} 3$ & 26 & $6 \cdot 3$ & 3500 & 212 & $6 \cdot 1$ & 1.03 \\
\hline & $\mathbf{I}$ & 420 & 34 & $8 \cdot I$ & 3500 & $26 \mathrm{I}$ & $7 \cdot 5$ & 1.08 \\
\hline \multirow{3}{*}{ J.F.L. } & 2 & 410 & $4 I$ & 10.0 & 3500 & 347 & $9 \cdot 9$ & $I \cdot O I$ \\
\hline & 3 & 420 & 39 & $9 \cdot 3$ & 3500 & 362 & $10 \cdot 3$ & 0.90 \\
\hline & 4 & 422 & 60 & $14 \cdot 2$ & 3500 & 344 & $9 \cdot 9$ & $(1 \cdot 43)$ \\
\hline \multirow{3}{*}{ F.S.W. } & $\mathbf{I}$ & 294 & II & $3 \cdot 4$ & 3500 & I 45 & $4 \cdot 1$ & 0.83 \\
\hline & 2 & 328 & 17 & $5 \cdot 2$ & 3500 & 219 & $6 \cdot 3$ & 0.83 \\
\hline & 3 & 329 & 19 & $5 \cdot 8$ & 3500 & $26 I$ & $7 \cdot 4$ & 0.79 \\
\hline \multirow{3}{*}{ G.R.H. } & $\mathbf{I}$ & 294 & 14 & $4 \cdot 8$ & 3500 & 152 & $4 \cdot 3$ & $I \cdot I 2$ \\
\hline & 2 & 328 & 19 & $5 \cdot 8$ & 3500 & 217 & $6 \cdot 2$ & 0.93 \\
\hline & 3 & 329 & 22 & $6 \cdot 7$ & 3500 & $25 \mathrm{I}$ & $\begin{array}{l}7 \cdot 2 \\
\text { Mean o. }\end{array}$ & $=0.04$ \\
\hline
\end{tabular}

${ }^{85} \mathrm{Sr}$. Both radioactive markers were therefore biologically incorporated. Urine and faeces were collected daily and blood samples were taken from the subjects at intervals over the experimental period. The blood samples were used to assay the plasma concentration of ${ }^{85} \mathrm{Sr}$ at various times during the experiment. Relative availability of $\mathrm{Sr}$ from the flour and milk was measured as the ratio of the urinary output to the dietary intake of ${ }^{90} \mathrm{Sr}$ divided by the ratio of the urinary output to the dietary intake of ${ }^{85} \mathrm{Sr}$.

\section{Results for the relative arailahility of Sr from flour and milk}

The values in Table 2 show the results obtained. Column 5 gives the ratio of the availability of $\mathrm{Sr}$ in flour to that in milk. For the five subjects, the mean relative availability with its standard error was $0.94 \pm 0.04$. This mean does not include the result for J.F.L. in the $4^{\text {th }}$ week, which appeared to be quite exceptional. For T.E.F.C. it would appear that the availability of the Sr from flour was rather less than from milk, and this individual discrepancy might well have been repeated had the experiment been extended to include a greater number of subjects.

\section{General inference from the results}

It would appear that when bread and milk are ingested at the same time, i.e. during a meal, the process of digestion ensures a mixing of food components so that the absorption of $\mathrm{Sr}$, and most probably of $\mathrm{Ca}$ as well, takes place from a composite mixture. Other experiments carried out at this Laboratory (Carr, Harrison 
$\&$ Sutton, 1962) have shown that $\mathrm{Sr}$ in milk may be regarded as fully available. The ratio of urinary output to dietary intake of $\mathrm{Sr}$ in milk was shown to be equal to that for a weak solution of $\mathrm{SrCl}_{2}$. The absolute availability of $\mathrm{Sr}$ in milk could not be compared with that of $\mathrm{Sr}$ in the mixed bread and milk diet of this experiment. It seems possible, however, that though the availability of $\mathrm{Sr}$ from bread and milk in a mixed diet is approximately equal, the overall availability from the mixed diet is less than that from milk alone owing to the phytate content of the flour. In fact, the results of the bread and milk experiment might well have been different had the milk been drunk between meals of bread and the other dietary constituents.

\section{Urine output and plasma concentrations of radiostrontium for the subjects while on the diet}

Figs. I and 2 show typical results for the plasma concentrations and daily urine output of ${ }^{85} \mathrm{Sr}$ for two of the experimental subjects during the period on the radioactive diet. Similar curves were obtained for the other volunteers. The level of ${ }^{\circ} \mathrm{Sr}$ in the diet was such that no measurements were attempted on the relatively small plasma samples used for the assay of ${ }^{85} \mathrm{Sr}$, nor was the daily output of ${ }^{90} \mathrm{Sr}$ in urine determined. There is no reason to expect, however, that the general pattern of the concentration in plasma or the daily urinary output of ${ }^{80} \mathrm{Sr}$ would have differed from that for ${ }^{85} \mathrm{Sr}$.

From Figs. $I$ and 2 it will be seen that the concentration of ${ }^{85} \mathrm{Sr}$ in plasma and consequently the daily output in urine increased relatively rapidly for about 7-10 days and thereafter increased much more slowly. The rapid rise in the concentration of the radioactive marker in plasma during the ist week is ascribed to a tendency toward a relatively rapid equilibration between the diet and the body fluids. For

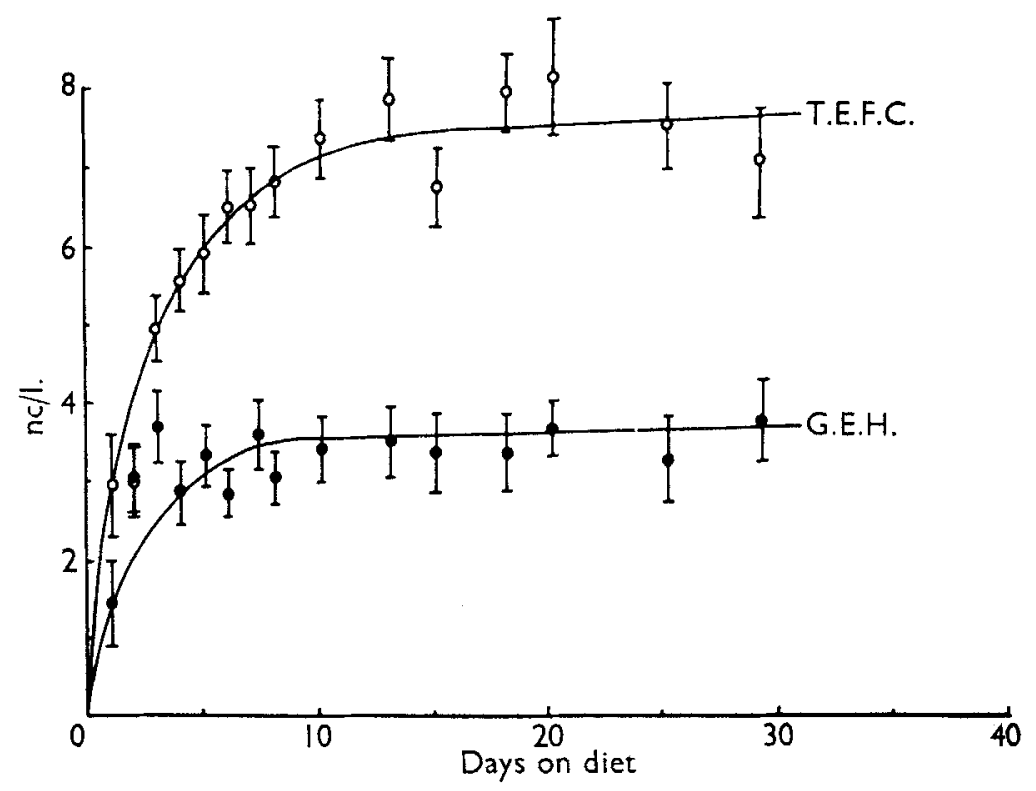

Fig. I. Concentration of the radioactive marker, ${ }^{85} \mathrm{Sr}$, in the plasma of human subjects while on a constant diet. The vertical lines through the points show the experimental error in each determination. 


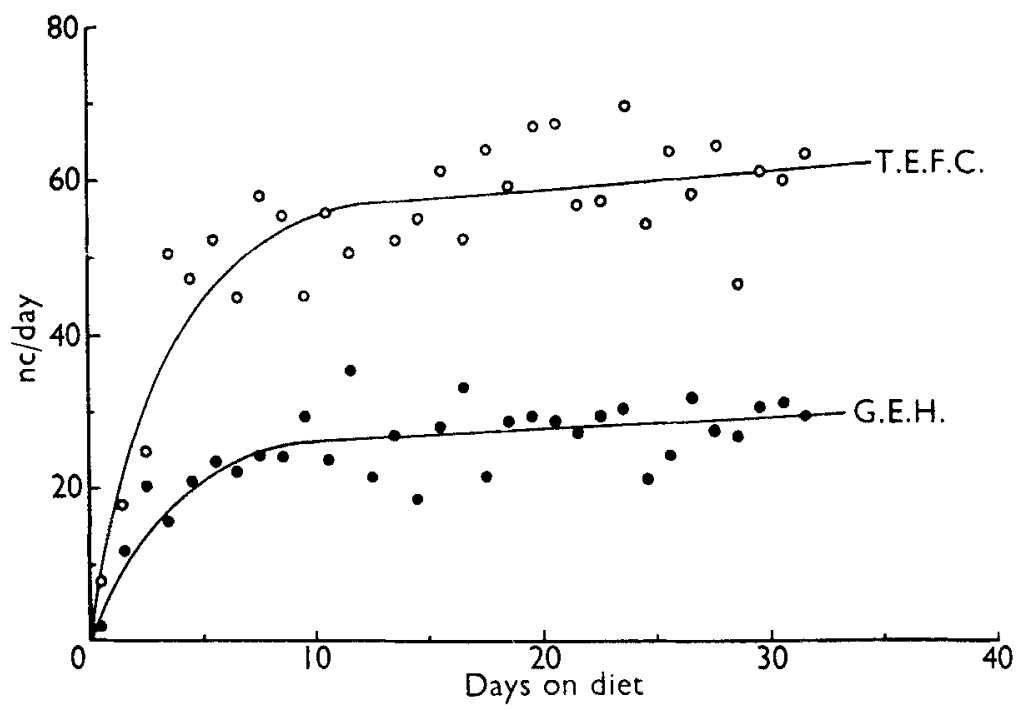

Fig. 2. Daily output in urine of the radioactive marker, ${ }^{85} \mathrm{Sr}$, by human subjects while on a constant diet.

bone-seeking tracers, such as $\mathrm{Sr}$, a much slower process of equilibration takes place between the bone and diet. Thus, the tendency toward the relatively rapid radioactive equilibrium between body fluids and the diet seen in Figs. I and 2 is modified by the transfer of radioactive ${ }^{85} \mathrm{Sr}$ from blood to bone and the return of inactive $\mathrm{Sr}$ from bone to blood. Since body stores of $\mathrm{Sr}$, like those of $\mathrm{Ca}$, are localized in bone, the latter process involves exchange of radioactive $\mathrm{Sr}$ and stable $\mathrm{Sr}$ between two body compartments represented by the body fluids on the one hand and the much larger bone compartment on the other.

Mention should be made of the relatively large variations in the daily urinary output of ${ }^{85} \mathrm{Sr}$ even after 3 or 4 weeks on the diet (Fig. 2). This variation amounted to sometimes as much as $30 \%$ and was much greater than the experimental error of any single observation. After the Ist week on the diet, it will be seen from Table 2 that, for a given subject, the weekly output of ${ }^{85} \mathrm{Sr}$ in urine differed by only a few percentage units. The cause of this daily variation in the urinary output is uncertain. Somewhat similar variations in urinary output have been noted for other elements including metabolites such as sodium, potassium and calcium (Stanbury \& Thomson, r95 I; Nicolaysen, Eeg-Larsen \& Malm, I953). Whatever be the cause, the effect is of special importance in connexion with studies of the availability of trace elements whether of mineral or plant origin.

\section{Specific activity of $S r$ in diet and urine}

To assess the quantitative effect of this transfer of Sr between body fluids and bone on the equilibrium between diet and body fluids, it is of interest to determine the specific activity of $\mathrm{Sr}$ in the diet and urine. The results are shown in Table 3 and the final column of the table gives the mean specific activities of Sr referred to both the 
Table 3. Intake and urinary output of stable strontium of subjects on the experimental diet with the mean specific activities of $\mathrm{Sr}$ referred to ${ }^{85} \mathrm{Sr}$ and ${ }^{90} \mathrm{Sr}$

\begin{tabular}{|c|c|c|c|c|c|c|c|}
\hline \multirow[b]{3}{*}{ Subject } & \multirow{3}{*}{$\begin{array}{l}\text { Week } \\
\text { on } \\
\text { diet }\end{array}$} & \multirow{2}{*}{\multicolumn{2}{|c|}{$\mathrm{Sr}$ (mg/week) }} & \multicolumn{4}{|c|}{ Mean specific activity of $\mathrm{Sr}$} \\
\hline & & & & & & & \\
\hline & & \multirow{2}{*}{$\begin{array}{c}\text { Intake } \\
6 \cdot 9\end{array}$} & \multirow{2}{*}{$\begin{array}{c}\text { Urinary } \\
\text { output } \\
\text { I } 7\end{array}$} & \multirow[t]{2}{*}{$\begin{array}{c}{ }^{85} \mathrm{Sr} \\
(\mathrm{nc} / \mathrm{mg})\end{array}$} & \multirow[t]{2}{*}{$\begin{array}{c}{ }^{90} \mathrm{Sr} \\
(\mathrm{pc} / \mathrm{mg})\end{array}$} & \multirow[t]{2}{*}{$\begin{array}{c}{ }^{85} \mathrm{Sr} \\
\text { (nc/mg) }\end{array}$} & \multirow[t]{2}{*}{$\begin{array}{c}{ }^{90} \mathrm{Sr} \\
(\mathrm{pc} / \mathrm{mg})\end{array}$} \\
\hline \multirow{3}{*}{ T.E.F.C. } & $\mathbf{I}$ & & & & & & \\
\hline & 2 & $\begin{array}{l}7 \cdot 0 \\
6.8\end{array}$ & I. 4 & \multirow[t]{2}{*}{$53^{\circ}$} & \multirow[t]{2}{*}{67} & \multirow[t]{2}{*}{318} & \multirow[t]{2}{*}{28} \\
\hline & $\begin{array}{l}3 \\
4\end{array}$ & $\begin{array}{l}0.8 \\
7.0\end{array}$ & $\begin{array}{l}\text { I. } 3 \\
\text { I. } 4\end{array}$ & & & & \\
\hline \multirow{4}{*}{ G.E.H. } & $\mathbf{I}$ & $6 \cdot 3$ & $1 \cdot 0$ & \multirow{4}{*}{$55^{\circ}$} & \multirow{4}{*}{69} & \multirow{4}{*}{240} & \multirow{4}{*}{33} \\
\hline & 2 & 6.3 & 0.88 & & & & \\
\hline & 3 & $6 \cdot 3$ & 0.80 & & & & \\
\hline & 4 & $6 \cdot 4$ & 0.83 & & & & \\
\hline \multirow{4}{*}{ J.F.L. } & $\mathbf{I}$ & 6.8 & I. 8 & \multirow{4}{*}{535} & \multirow{4}{*}{64} & \multirow{4}{*}{283} & \multirow{4}{*}{37} \\
\hline & 2 & $6 \cdot 5$ & $1 \cdot 4$ & & & & \\
\hline & 3 & $6 \cdot 2$ & I.I & & & & \\
\hline & 4 & $6 \cdot 7$ & $1 \cdot 2$ & & & & \\
\hline \multirow{3}{*}{ F.S.W. } & $\mathbf{I}$ & $8 \cdot 9$ & $1 \cdot 5$ & \multirow{3}{*}{385} & \multirow{3}{*}{35} & \multirow{3}{*}{185} & \multirow{3}{*}{14} \\
\hline & 2 & $9 \cdot 2$ & $1 \cdot 5$ & & & & \\
\hline & 3 & $9 \cdot 2$ & $1 \cdot \mathbf{1}$ & & & & \\
\hline \multirow{3}{*}{ G.R.H. } & $\mathbf{I}$ & $8 \cdot 2$ & $1 \cdot 3$ & \multirow{3}{*}{420} & \multirow{3}{*}{38} & \multirow{3}{*}{172} & \multirow{3}{*}{15} \\
\hline & 2 & 8.6 & 1.6 & & & & \\
\hline & 3 & $8 \cdot 1$ & $I \cdot I$ & & & & \\
\hline
\end{tabular}

radioactive markers. The specific activity of $\mathrm{Sr}$ in urine for the ist week on the diet is not included in the means shown for each subject because of the relatively rapid increase in the urinary output of ${ }^{85} \mathrm{Sr}$ over this period. It will be seen that the mean specific activity of $\mathrm{Sr}$ in the diet was about twice that in the urine for all subjects. From the relatively low specific activity of $\mathrm{Sr}$ in urine compared with that in the diet and the relatively slow change with time of the former (which may be inferred from Fig. 2), it may be concluded that full body equilibrium would only be achieved in a time which is many times greater than the duration of this experiment. Neglect of this long-term effect on the equilibrium between the various body compartments, especially with bone-seeking tracers, has often falsified conclusions drawn from short-term experiments.

\section{Conclusions}

The availability to man of $\mathrm{Sr}$ from flour, and possibly from other plant sources as well, is equal to that from milk in a mixed diet. The Sr in milk is fully available, but in a mixed diet the availability of Sr may well be determined by the overall constitution of the diet. Thus, phytates which are known to lower the availability of many minerals also lower the availability of $\mathrm{Sr}$, so that cereal-rich diets are likely to have the lowest availability of Sr.

For trace elements which are deposited in bone, such as $\mathrm{Sr}$, full equilibrium between body and diet is only achieved after a long period on the diet. A relatively rapid approach to equilibrium is to be expected between diet and body fluids, but full equilibrium will be delayed by the much slower equilibration of the trace element 
between the bone and diet, so that, if a trace element is incorporated in the diet for a short time, availability, assessed from the ratio of the urinary output to the dietary intake, may be considerably underestimated.

\section{REFERENCES}

Agricultural Research Council Radiobiological Laboratory. (1959). Report no. I. Bruce, H. M. \& Callow, R. K. (r934). Biochem. f. 28, 5 I 7.

Bryant, F. J., Chamberlain, A. C., Spicer, G. S. \& Webb, M. S. W. (1958). Brit. med. F. i, I371. Carr, T. E. F., Harrison, G. E., Loutit, J. F. \& Sutton A. (1962). Nature, Lond., 194, 200.

Carr, T. E. F., Harrison, G. E. \& Sutton, A. (1962). Proc. Soc. exp. Biol., N.Y., rxo, I5 I.

Comar, C. L., Russell, R. S. \& Wasserman, R. H. (1957). Science, 126, 485.

Harrison, G. E., Raymond, W. H. A. \& Tretheway, H. C. (1955). Clin. Sci. 14, 68I.

Kostial, K., Lutkić, A., Grunden, N., Vojvodić, S. \& Harrison, G. E. (1963). Int. Y. Radiat. Biol. 6, 431.

McCance, R. A. \& Widdowson, E. M. (1942-3). F. Physiol. ror, 304.

Mellanby, E. (1925). Spec. Rep. Ser. med. Res. Coun., Lond., no. 93.

Nicolaysen, R., Eeg-Larsen, N. \& Malm, O. J. (1953). Physiol. Rev. 33, 424.

Spencer, H., Laszlo, D. \& Brothers, M. (I957). F. clin. Invest. 36, 680.

Stanbury, S. W. \& Thomson, A. E. (1951). Clin. Sci. 10, 267.

Wasserman, R. H. \& Comar, C. L. (1960). Proc. Soc. exp. Biol., N.Y., 103, 124. 